\title{
Notes for Authors
}

Earth and Environmental Science Transactions of the Royal Society of Edinburgh publishes peer-reviewed original scientific research papers, reviews, and short communications on all fields across the broad spectrum of earth and environmental sciences. Articles do not need to have a specifically Scottish focus, nor are authors required to be Fellows of the Society. Articles should have relevance to a worldwide audience, even if the study is focused on a single geographic site. Papers should make topical, substantial and scholarly contributions; the Editors are keen to encourage interdisciplinary papers. Discussions of articles previously published in the Transactions and reviews of topics of current interest are also invited. There are no page charges; however, if fold-outs or colour illustrations are envisaged, the Journals Officer should be consulted prior to submission (publications@royalsoced.org.uk). All new submissions are sent to at least two reviewers.

\section{Submission}

Ideally, manuscripts should be submitted electronically, with separate text and figure files on disk or CD. (Text in WORD format; Tables in Excel; Figures as PDF files, preferably at publication size). These should be sent to the Journals Officer, The Royal Society of Edinburgh, 22-26 George Street, Edinburgh EH2 2PQ, Scotland, UK. Files can be emailed to publications@royalsoced.org.uk or sent through this link: http://journals.cambridge.org/action/manuscriptSubmission?jid=TRE (Figure files as low-resolution PDFs). Any queries regarding submission may be sent to the email address as above. Submissions to Earth and Environmental Science TRSE must not have been published, or be under consideration, elsewhere.

\section{Preparation of papers}

2.1. Title page

The first page should show (a) a title that is concise and informative, (b) the name(s) and full addresses(es) of the author(s); and (c) a running head abbreviation of the title of not more than 50 characters. Papers by more than one author must be submitted with statements from all the authors, approving the paper in its entirety and its submission to EESTRSE, and naming the author responsible for correspondence.

\subsection{Abstract and Key Words}

The second page should contain an abstract of not more than 200 words, intelligible without reference to the text or references, and a list of key words (not already in the title) of no more than 150 characters, in alphabetical order.

\subsection{Text}

Text should start on the third page. Words to be printed in italics, e.g. names of taxa, should be underlined, unless already in italic typeface. Use capital letters for formal terms only. The metric system should be used throughout. Abbreviate compass points to N, NW, NW, SE etc. Enclose map references in square brackets, e.g. [NM 4437 0293]. In papers on systematic palaeontology, anatomical abbreviations should be included in the relevant Figure captions, rather than listed in a separate section. See a recent issue for general systematics style.

\subsection{Headings}

The introductory section requires no heading. The first section after the introduction should be numbered as section 1 . Primary headings are numbered consecutively $1,2,3$, etc. Secondary headings are 1.1., 1.2., 1.3., etc. Both should appear flush left, with their text starting on a separate line below. Tertiary headings (1.1.1., 1.1.2., etc) should start a new paragraph, with indent, and should be followed by a full stop and the text to which they refer. All headings should be in bold. Cross-references in text should be to a section, e.g. (see section 2.3), not to a page. See a recent issue of the journal for these style matters.

\subsection{Footnotes}

Do not use footnotes.

\subsection{References}

All publications cited in the text, including those pertaining to the authorship of all taxa, must be included in the Reference list, which is arranged in alphabetical order by author.

2.6.1. Citations in text. These should appear as in the following examples: (a) Jennings \& Smith (1967) record that.... .; (b) It has been recorded (James 1931) or (Jennings \& Smith 1969, p.32) or (Jenkins 1947, 1950; Jenkins \& Brock 1975) that......

('Pers. comm.' citations in the text should include the name of the person and the date (year) of the communication; these should not be included in the Reference list.)
2.6.2. References at end. Only published or in press items, or unpublished Theses with the University clearly specified, are to be included in the References. Journal and series titles should be written out in full, upper and lower case italics.

References at the end should be ordered thus:

(i) single author - by date (and alphabetical by initials) e.g. Smith, A. B. 1990; Smith A. B. 1996; Smith, C. D. 1989 Smith, C. D. 1990

(ii) author plus two or more co-authors (et al.) - by date e.g.: Smith, Jones \& Clerk 1993; Smith, Brown \& Clerk 1995; Smith, Clerk, Brown \& Jones 1997

(iii) author plus one other - alphabetical by 2nd author e.g.: Smith \& Brown 1997; Smith \& Jones 1987

Set out as indicated below:

Copper, P. \& Gourvennec, R. 1996. Evolution of the spire-bearing brachiopods, (Ordovician-Jurassic). In Copper, P. \& Jin, J. (eds) Brachiopods, 81-88. Rotterdam: A. A. Balkema.

Chappell, B. W. \& White, A. J. R. 1992. 1- and S-type granites in the Lachlan Fold Belt. Transactions of the Royal Society of Edinburgh: Earth Sciences 83, 1-26.

Jarvik, E. 1980. Basic structure and evolution of vertebrates, Vol. 1, 74 98. London: Academic Press.

\section{Preparation of Tables and Illustrations}

3.1. Tables

Tables should be numbered consecutively on separate pages and should follow the text and References in the MS. Each table should have a caption. For layout of analytical data see tables published in previous issues. Authors will be asked to send published analyses of igneous rocks to the UK IGBA file.

\subsection{Illustrations}

Number illustrations consecutively through the paper. A list of figure captions should be provided on a separate page; figures and figure captions should not be embedded in the text. Where appropriate, group material into one figure and label a, b, c, etc. In the case of groups of photographs, labels and annotation should be on the photograph, not on the space between photographs. Ensure that the size of lettering after reduction will be legible (not less than 6 point). A scale should be shown on the figure (e.g., a bar scale on a photomicrograph), rather than giving magnifications in the caption, in case figures are reduced or enlarged. Large figures can be subdivided for reproduction on facing pages. Fossil illustrations should be illuminated top left. Figures in PDF format are sufficient for submission purposes. Should a paper be accepted for publication, high quality files will be requested. For electronic files of figures, use standard software and supply files saved in native file format, together with TIF or EPS where possible. Guidelines for their production are available on request from the RSE's Journals Officer.

\section{Proofs and offprints}

A PDF proof of an accepted paper will be sent to the corresponding author. 25 offprints (with covers) of the published paper are provided gratis and additional copies of offprints may be ordered (in batches of 25) when checked proofs are returned. An electronic PDF of the published paper (the "publisher's version") can be supplied on request.

\section{Copyright}

On acceptance, authors will be asked to assign copyright of their papers to the Royal Society of Edinburgh. They are also asked to ensure that any electronic versions clearly state the official place of publication. 


\section{Earth and Environmental Science \\ Transactions of the Royal Society of Edinburgh}

Volume 1022012 (for 2011) Part 3

Sarah E. STEWART

Distribution and palaeoecology of Ordovician bivalves and gastropods from Girvan, SW Scotland

145-158

Stig M. BERGSTRÖM, Mark KLEFFNER and Birger SCHMITZ

Late Ordovician-Early Silurian $\delta^{13} \mathrm{C}$ chemostratigraphy in the Upper Mississippi Valley: implications

for chronostratigraphy and depositional interpretations

159-178

E. L. SHARP and J. A. CLACK

Redescription of the lungfish Straitonia waterstoni from the Viséan of Lothian, Scotland

179-189

Tim C. KINNAIRD, David C. W. SANDERSON and Naomi WOODWARD

Applying luminescence methods to geoarchaeology: a case study from Stronsay, Orkney

191-199

\section{Transactions available on-line}

Earth and Environmental Science Transactions of the Royal Society of Edinburgh is available on subscription as both print plus online and online only. (Online ISSN: 1755-6929)

As from 2007 (volume 98) this journal is included in the Cambridge Journals Online (CJO) service which can be found at http://journals.cambridge.org/tre

This page on the CJO site also includes a link to back issues of the journal (Volumes 92 (2001) to 97 (2006)) under its former title Transactions of the Royal Society of Edinburgh: Earth Sciences.

Feedback: All comments are welcome - either regarding the quality and usability of the electronic product or the process of registration online. Please send comments to: publications@royalsoced.org.uk

(Issue date 31 July 2012)

ISSN 1755-6910 TREASO 102 145-199 (2012, for 2011)

Published by the RSE Scotland Foundation, 22-26 George Street, Edinburgh EH2 2PQ

Typeset and printed by Henry Ling Limited, Dorchester, UK

Distributed and Marketed by Cambridge University Press, Cambridge, UK

The RSE Scotland Foundation, a charitable body connected to The Royal Society of Edinburgh, is Scottish Charity No. SC024636 